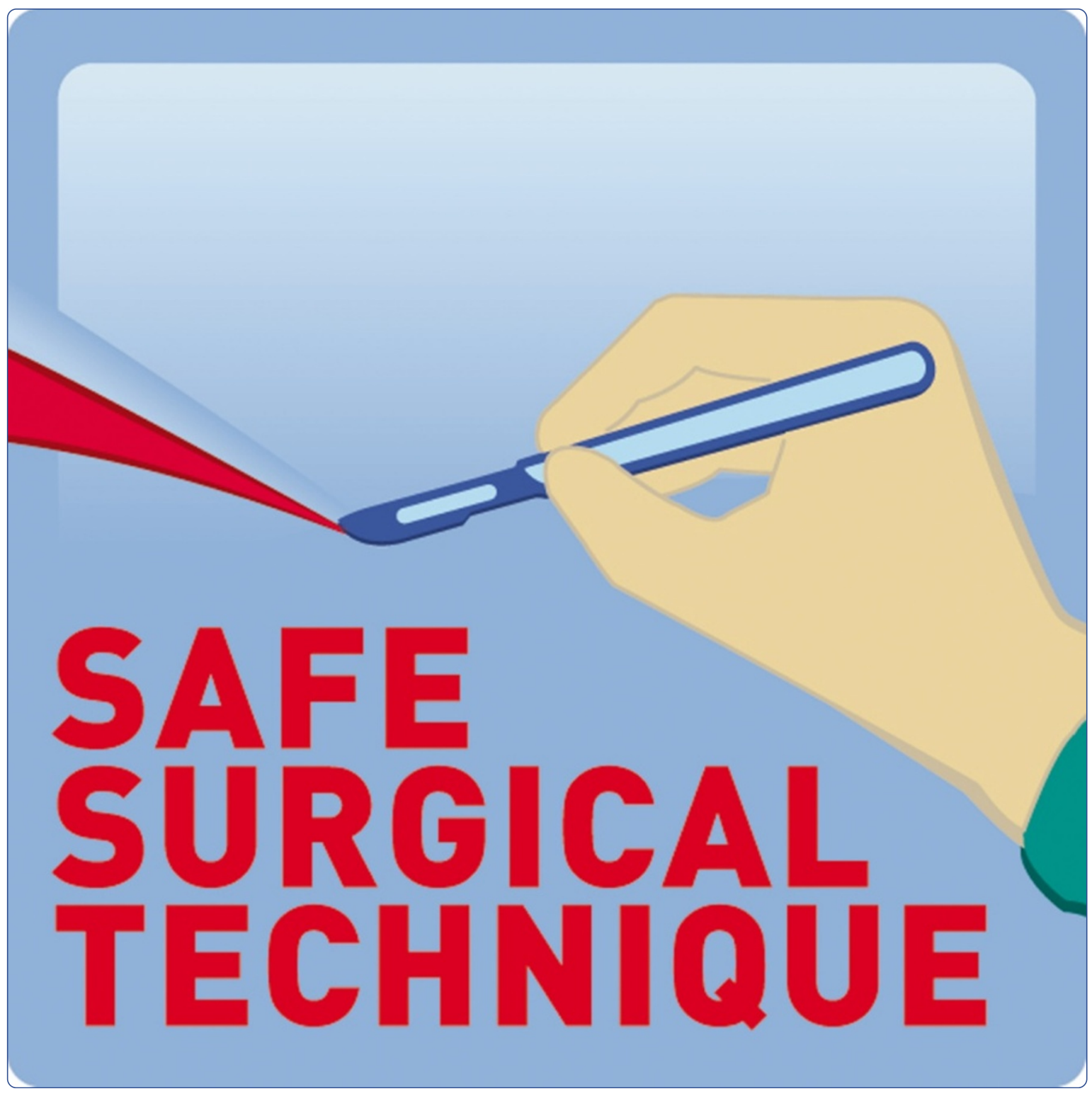

Safe surgical technique: cement-augmented pedicle screw instrumentation and balloon-guided kyphoplasty for a lumbar burst fracture in a 97-year-old patient

Freude et al.

( ) Biomed Central 


\title{
Safe surgical technique: cement-augmented pedicle screw instrumentation and balloon-guided kyphoplasty for a lumbar burst fracture in a 97-year-old patient
}

\author{
Thomas Freude ${ }^{1 * \dagger}$, Benjamin König ${ }^{1 \dagger}$, Frank Martetschläger ${ }^{2}$, Sebastian Siebenlist ${ }^{2}$, Markus Neumaier $^{2}$, \\ Ulrich Stöckle ${ }^{1}$ and Stefan Döbele ${ }^{1}$
}

\begin{abstract}
Background: During the last few years, an increasing number of unstable thoracolumbar fractures, especially in elderly patients, has been treated by dorsal instrumentation combined with a balloon kyphoplasty. This combination provides additional stabilization to the anterior spinal column without any need for a second ventral approach.

Case presentation: We report the case of a 97-year-old male patient with a lumbar burst fracture (type A3-1.1 according to the $\mathrm{AO}$ Classification) who presented prolonged neurological deficits of the lower limbs - grade $C$ according to the modified Frankel/ASIA score. After a posterior realignment of the fractured vertebra with an internal screw fixation and after an augmentation with non-absorbable cement in combination with a balloon kyphoplasty, the patient regained his mobility without any neurological restrictions.

Conclusion: Especially in older patients, the presented technique of PMMA-augmented pedicle screw instrumentation combined with balloon-assisted kyphoplasty could be an option to address unstable vertebral fractures in "a minor-invasive way". The standard procedure of a two-step dorsoventral approach could be reduced to a one-step procedure.
\end{abstract}

Keywords: Thoracolumbar fracture, Augmented screws, Kyphoplasy, Spine fracture in elderly

\section{Background}

Burst fractures of the thoracolumbar spine have the highest incidence rate of spine fractures. There is a consensus that stable fractures are treated conservatively [1]. For unstable burst fractures, the surgical approach still presents a topic of discussion [2-4]. The posterior spinal instrumentation with pedicle screws allows an indirect fracture reduction and prevents consecutive kyphosis [5,6]. Due to a high prevalence of early instrumentation failure, an additional stabilization of the anterior spinal column with strut grafting, plates, and mesh cages via a second anterior approach has been reported with sufficiently positive clinical results

\footnotetext{
* Correspondence: Thomas.freude@gmx.de

${ }^{\dagger}$ Equal contributors

'Department of Traumatology, Eberhard Karls Universität Tübingen,

Schnarrenbergstrasse 95, 72076, Tübingen, Germany

Full list of author information is available at the end of the article
}

[4,7-9]. The second approach, however, is associated with an increased morbidity, a longer operation time, higher blood loss and high donor site morbidity $[2,10]$.

In the recent literature, a new technique, in which dorsal instrumentation is combined with a balloon kyphoplasty in order to address these problems, has been introduced. For acute traumatic compression or burst fractures, promising clinical results have been demonstrated in young adults when absorbable bone cement was used for the kyphoplasty [4,11-13]. But especially in older patients with an osteoporotic bone structure, an integration of absorbable bone cement cannot be expected [14].

This case report describes the safe technique in 97-year old patient with a lumbar burst fracture and neurological deficits, treated by cement-augmented pedicle screw instrumentation and balloon-guided kyphoplasty. To our 
knowledge, this surgical procedure has not yet been reported in a patient of such a high age and accompanying neurological symptoms.

\section{Case presentation}

A 97-year-old man in good age-corresponding condition had fallen from a standing height. At the time of his initial visit at our hospital, the CT scans indicated a multifragmentary endplate fracture involving the posterior edge of the L2 vertebral body as well as a considerable narrowing of the spinal channel (Magerl Classification type A3-3.1 [3]). Initially, the patient denied surgical intervention. At this time, no neurological deficit was detected. Because of severe pain and a progressive weakness of the lower limbs - grade $\mathrm{C}$ according to the modified Frankel/ASIA score [15] - the patient attended our department again on the following day. The follow-up CT scan revealed a progression of the vertebral compression and an increased bulging of the dorsal wall into the spinal cord space (Figure 1).

Because of the patient's good age-corresponding condition, it was decided to perform a posterior decompression by distraction and lordosation using an augmented pedicle screw instrumentation with non-absorbable bone cement. In a one-step procedure, an additional balloon-assisted kyphoplasty was performed in order to support the anterior column (see below: Safe Surgical Technique). The operative time was $72 \mathrm{~min}$. Intraoperatively, there was no complication. A 48-hour monitoring which was carried out after the surgical intervention at the intensive care unit was uneventful. The monitoring in the ICU was only due to the advanced age of the patient and was outside the normal treatment guidelines. No sensomotoric deficit was detected during the wholein-patient-stay-grade E according to the modified Frankel/ASIA score [15]. The day after the surgical procedure, the patient was started with doing exercises, including having dinner while sitting upright in his bed. During his physical therapy, the patient was fairly pain-free (VAS $=3$ ), and moved around using a walking frame. Ten days after the surgery, the patient was discharged. Due to the poor bone quality, that had been discovered during the insertion of the pedicle screws, and the obvious senile osteoporosis, we started with an oral anti-osteoporosis therapy with the application of bisphosphonate $75 \mathrm{mg} /$ week, calcium $1000 \mathrm{mg} / \mathrm{d}$ and cholecalciferol $500 \mathrm{mg} / \mathrm{d}$, with the advice that it should be continued after the patient had been sent home.

At 12 months follow-up the patient is completely remobilized and had regained his pre-injury level of activity. He is able to walk over a distance of $2 \mathrm{~km}$ without any pain. He is taking part in his normal social life and is living in complete independence without any need of support (Table 1). CT-scans (Figure 2) showed no

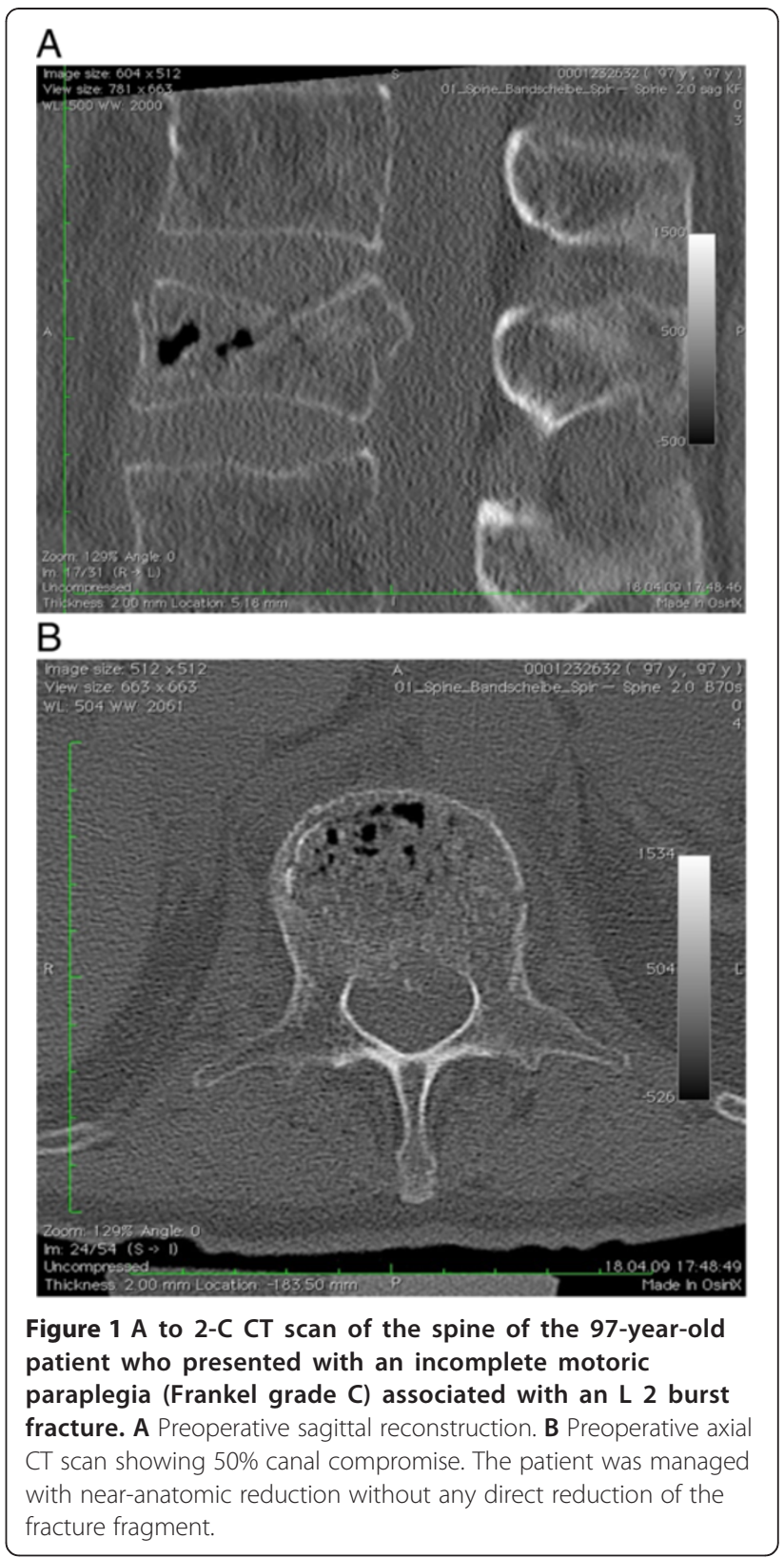

secondary dislocation of the screws and no signs of instability in the kyphoplasted vertebra.

\section{Safe surgical technique}

The surgery was performed under general anaesthesia. The patient was placed prone on a radiolucent table. A partial reduction of the kyphotic deformity was obtained under image intensifier control. For dorsal instrumentation, the Synthes USS system (Synthes, Solothurn, Switzerland) was used. Four Schanz pedicle screws (diameter of $6 \mathrm{~mm}$, thread length of $45 \mathrm{~mm}$ ) were placed transpedicularly on both sides into the body of the non-fractured vertebrae cephalad and 
Table 1 Showing the Oswestry [16-18]

\begin{tabular}{|c|c|c|c|c|c|c|}
\hline & Pre-admission & Admission & $24 h$ post $O P$ & $12 d$ post $O P$ & 6 months post OP & 12 months post $O P$ \\
\hline Oswestry (\%) & 100 & 0 & 22 & 48 & 93 & 93 \\
\hline VAS & 0 & 10 & 5 & 2 & 0 & 0 \\
\hline Frankle/ASIA & E & C & $E$ & $\mathrm{E}$ & $\mathrm{E}$ & $E$ \\
\hline Morpine & - & + & + & - & - & - \\
\hline Analgetics & - & + & + & + & - & - \\
\hline Calcium & - & - & - & 1000 mg/day & $1000 \mathrm{mg} / \mathrm{d}$ & $1000 \mathrm{mg} / \mathrm{d}$ \\
\hline Bisphosphonates & - & - & - & 75 mg/week & $75 \mathrm{mg} /$ week & $75 \mathrm{mg} /$ week \\
\hline Cholecalciferol & - & - & - & 500 mg/day & 500 mg/day & 500 mg/day \\
\hline
\end{tabular}

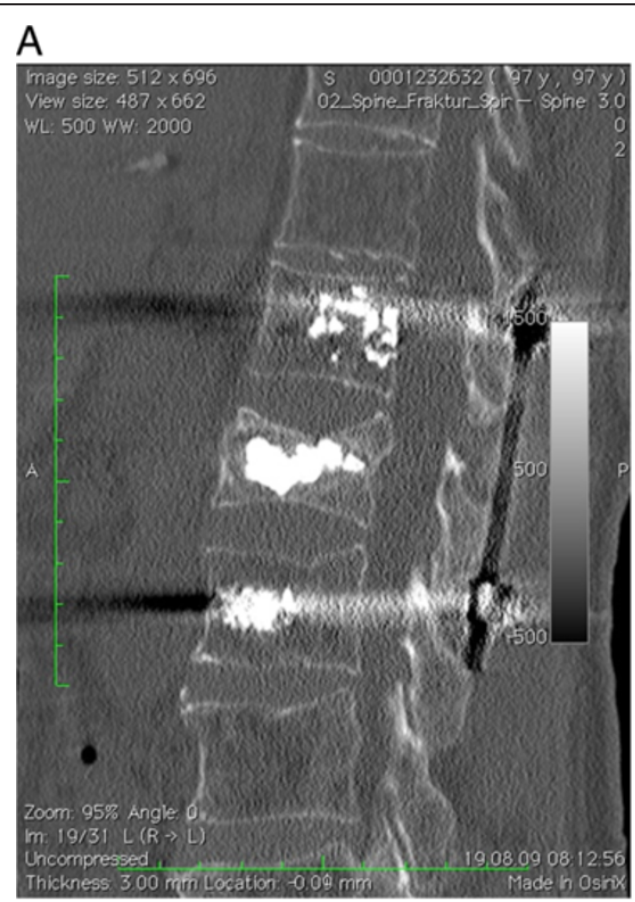

B

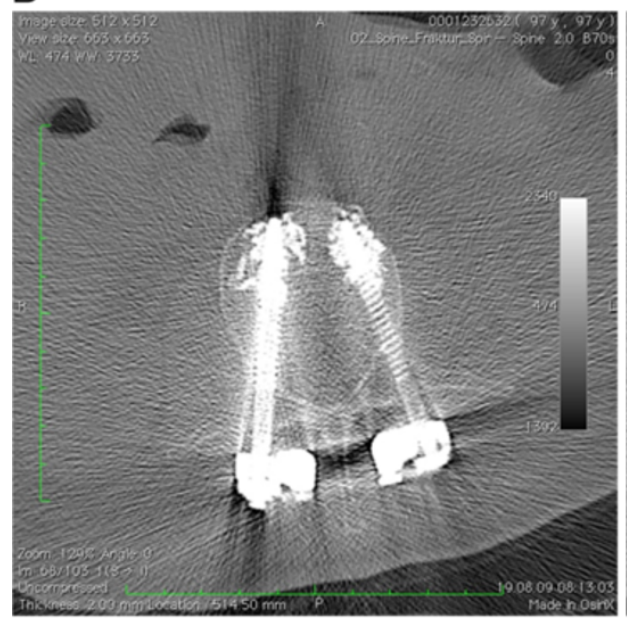

C

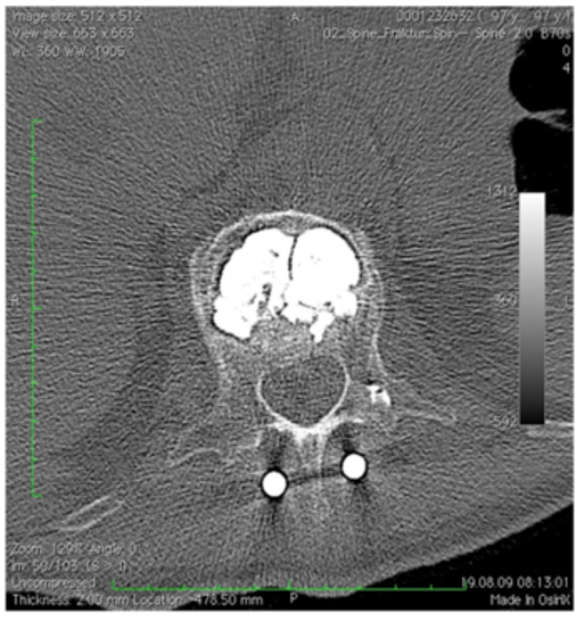

Figure 2 A Sagittal reconstruction CT scan showing the well-maintained restoration of the vertebral body height $r$ and sagittal alignment with augmented cephal and caudal screws. B Cement augmentation of the pedicel screws. C Axial CT scan showing no residual canal stenosis and the filling of the vertebral body with PMMA cement through the kyphoplasty technique. 
caudad to the fractured vertebra, through the use of a standard longitudinal midline incision. Afterwards, the screws were removed and the prepared nonabsorbable cement $\left(K_{y p h X}{ }^{\circledR} \mathbf{H V}-\mathbf{R}^{\mathrm{TM}}\right.$, Kyphon Inc., Sunnyvale, USA) was applied into the non-fractured vertebra with a trokar in order to ensure a greater stability of the screws in the osteoporotic bone. After the cement had completely hardened, the screws were connected with two titanium rods with a length of $7.4 \mathrm{~cm}$. Further fracture reduction was obtained through the use of distraction tools in order to restore anatomic alignment under the control of an image intensifier. The fragments may have occurred as a result of ligamentotaxis. The fracture fragments were neither exposed or directly manipulated, nor was any kind of open reduction, decompression laminectomy or laminotomy performed. After that, the kyphoplasty of the fractured first lumbar vertebra was carried out with the KyphX-balloon system (Kyphon, Sunnyvale, California, USA). At first, the pedicle finder was used in order to open both pedicles of the fractured vertebra and to create a transpedicular pathway within the fractured vertebral body. This opening of the pedicles was carried out under image intensifier guidance. Next, two trokars with a diameter of $4.2 \mathrm{~mm}$ were inserted in the predrilled pedicle pathways. The trokars were used as guidance for the two $20 \mathrm{~mm}$ kyphoplasty balloons. Under image intensifier monitoring, both were inflated up to $150 \mathrm{psi}$ and $4 \mathrm{ccm}$. During this procedure, the dorsal wall of the vertebral body was carefully observed in order to avoid its dislocation into the spinal cord space. After the normal vertebral height had been restored with the kyphoplasty balloons, the newlyformed cavity was carefully filled with non-absorbable cement $\left(\mathrm{KyphX}^{\circledR} \mathbf{H V}-\mathbf{R}^{\mathrm{TM}}\right.$, Kyphon INC., Sunnyvale, USA) under biplanar control. The wound cavity was flushed and haemostasis was achieved. The intraoperative blood loss amounted to $200 \mathrm{ml}$. The patient did not require any intra-/or postoperative transfusion of blood products.

\section{Conclusion}

Thoracolumbar burst fractures still are a great challenge to surgeons, especially in elderly patients with osteoporotic bones. In old and very old patients, early mobilization has to be the primary goal in order to reduce the time of the hospital stay and to decrease the morbidity and the mortality respectively. The short-segment posterior pedicle screw instrumentation is a well-accepted technique for the reduction and stabilization of vertebral burst fractures $[4,11,19]$. According to the long-term follow-up results that have been gathered over the last decades, the exclusive stabilization with this technique seems to be insufficient. The reported failure rate varies from 20 to $50 \%$ in the case of pedicle screw failure and a consecutive increase of spinal kyphosis $[8,20]$. Therefore, additional anterior procedures are recommended. The anterior approach allows a full visualization of the fracture. The use of plates, cages or iliac cortical grafts facilitates the direct vertebral restoration, the decompression and a solid fusion. Although the anterior approach leads to an extended operation time, the more traumatic ventral approach, on the contrary, leads to a higher blood loss and an elevated postoperative morbidity.

During the last decade, the dorsal instrumentation in combination with absorbable cement augmentation techniques has become increasingly popular for younger patients [13,14,19]. Marco and Kushwaha [4] treated 39 patients with a mean age of 38 years, with or without a neurological deficit, with a short-segment instrumentation in combination with a calcium phosphate cement reconstruction. They claimed that an excellent lasting reduction of unstable burst fractures had been achieved during a 2-year-follow-up with the use of this combined technique. Nevertheless, some complications were observed: Screw breakage was recorded in two patients, wound dehiscence was observed in one patient and finally a pseudarthrosis of the dorsolateral fusion in another. Cement leakage was not observed at all though. However, patients with senile osteoporosis were excluded. Cho et al [12]. reported on a group of 70 patients (mean age 45 years) 50 of whom were treated by short-segment pedicle-screw instrumentation alone while the remaining 20 were treated by combined reinforced PMMA vertebroplasty. In the first group, implant failure was observed in $22 \%$ of the patients and after a two-year follow-up, an increase of the kyphotic deformity of 6.2 degrees was recorded. No implant failure was observed in the second group, where the increase of the kyphotic deformity was amounted to only 0.3 degrees. In 1998, Mermelstein et al [21]. already conducted a biomechanical study in which the reinforcement of the thoracolumbar burst fractures with calcium phosphate cement in a cadaver model of an L1 burst fracture was observed. A decrease of the pediclescrew bending moments of 59\% in flexion and of 38\% in extension was observed. Therefore, it was concluded that this combined technique may improve the patient's outcome without a secondary anterior procedure. In a study of Verlaan et al $[13,14]$. the height of the fractured vertebral body could be restored at up to $91 \%$ of the estimated intact height in 20 patients with transpedicular balloon vertebroplasty in combination with posterior instrumentation. Korovessis et al [2]. included 23 patients with a mean age of 48 years in a prospective study with balloon kyphoplasty using calcium phosphate and stabilization with pedicle screw instrumentation and fusion. After a follow-up of 24 months, an improvement of the kyphosis deformity as well as of the vertebral body weight ratio was reported. 
Only a few cases of dorsal internal fixation in combination with cement augmentation techniques for older patients with osteoporotic bones, have been reported in the current literature [22-24]. The case of a 97-year-old male with a lumbar burst fracture that is presented here, illustrates the use of a dorsal pedicle screw instrumentation not only in combination with a balloon-assisted kyphoplasty but also with additional cement-augmented pedicle screws. To our knowledge, this technique has not yet been reported for a patient of this age. For this one-step-procedure with a non-absorbable bone cement augmentation, we decided to provide more stability in a severe osteoporotic bone in order to prevent secondary cutting-out or screw loosening. Our patient recovered quickly and could be remobilized without any pain. Because of the use of this technique, no additional anterior approach was necessary. Therefore, this technique lead to a reduction of the operative trauma and the risk of postoperative wound complications as well as of the morbidity and the length of the stay in hospital. Wound infection or necrosis did not occur at all. At this high age, multiple complications can result in a prolonged wound healing. Local infection rates after dorsoventral approach ranged between $7 \%$ and 14\% [25-27]. The next problem consists in the osteoporotic vertebrae themselves: We were able to observe fractures of the vertebrae in the next segment that was located caudal or cephalad to the fixateur interne. These fractures were manly located cephalad, because of the increased stress and forces that were caused the stabilisation. It should always be discussed how many segments have to be addressed in order to provide enough stability to prevent the next fracture. The use of cement to augment the screws provides more stability for the osteoporotic bone, but the removal of the screws is very problematic and associated with a high incidence of collateral damage.

Especially in older patients, the presented technique of PMMA-augmented pedicle screw instrumentation combined with balloon-assisted kyphoplasty could be an option to address unstable vertebral fractures in "a minor-invasive way". In order to minimize the surgical morbidity and to increase the quality of life, the standard procedure of a two-step dorsoventral approach has to be reduced to a one-step procedure.

\section{Consent}

Written informed consent has been obtained from the patient for the publication of this case report and any accompanying images. A copy of the written consent is available for review for the editor-in-chief of this journal.

\section{Competing interests}

The authors declare that they have no competing interests. There are no financial interests by any of the authors with regard to the companies whose products are described in this paper, i.e. Kyphon/Medtronic and Synthes.

\section{Authors' contribution}

All authors have made a significant contribution to the different steps of the processing of the patient's history as well as to the writing and the editing of the manuscript. TF and SD have conceived the idea for the study and have written the first draft. SS has provided research support and advice throughout the project. Furthermore, FM and BK have provided expertise in artwork. The corresponding author TF and US have carried out the surgical procedures and have provided geriatric expertise. All authors have read and approved the final manuscript.

\section{Author details}

'Department of Traumatology, Eberhard Karls Universität Tübingen, Schnarrenbergstrasse 95, 72076, Tübingen, Germany. ²Department of Traumatology, Klinikum Rechts der Isar, Technische Universität Muenchen, Ismaninger Strae 22, 80809, Munich, Germany.

Received: 15 December 2012 Accepted: 3 January 2013

Published: 8 January 2013

\section{References}

1. Wood K, Buttermann G, Mehbod A, Garvey T, Jhanjee R, Sechriest V: Operative compared with nonoperative treatment of a thoracolumbar burst fracture without neurological deficit. A prospective, randomized study. J Bone Joint Surg Am 2003, 85-A:773-781.

2. Korovessis P, Repantis T, Petsinis G, lliopoulos P, Hadjipavlou A: Direct reduction of thoracolumbar burst fractures by means of balloon kyphoplasty with calcium phosphate and stabilization with pedicle-screw instrumentation and fusion. Spine (Phila Pa 1976) 2008, 33:E100-E108.

3. Magerl F, Aebi M, Gertzbein SD, Harms J, Nazarian S: A comprehensive classification of thoracic and lumbar injuries. Eur Spine J 1994, 3:184-201.

4. Marco RA, Kushwaha VP: Thoracolumbar burst fractures treated with posterior decompression and pedicle screw instrumentation supplemented with balloon-assisted vertebroplasty and calcium phosphate reconstruction. J Bone Joint Surg Am 2009, 91:20-28.

5. Aebi M, Etter C, Kehl T, Thalgott J: Stabilization of the lower thoracic and lumbar spine with the internal spinal skeletal fixation system. Indications, techniques, and first results of treatment. Spine (Phila Pa 1976) 1987, 12:544-551.

6. Dick W, Kluger P, Magerl F, Woersdorfer O, Zach G: A new device for internal fixation of thoracolumbar and lumbar spine fractures: the 'fixateur interne'. Paraplegia 1985, 23:225-232.

7. McCormack T, Karaikovic E, Gaines RW: The load sharing classification of spine fractures. Spine (Phila Pa 1976) 1994, 19:1741-1744.

8. McLain RF, Sparling E, Benson DR: Early failure of short-segment pedicle instrumentation for thoracolumbar fractures. A preliminary report. J Bone Joint Surg Am 1993, 75:162-167.

9. Mumford J, Weinstein JN, Spratt KF, Goel VK: Thoracolumbar burst fractures. The clinical efficacy and outcome of nonoperative management. Spine (Phila Pa 1976) 1993, 18:955-970.

10. Kaneda K, Taneichi H, Abumi K, Hashimoto T, Satoh S, Fujiya M: Anterior decompression and stabilization with the Kaneda device for thoracolumbar burst fractures associated with neurological deficits. J Bone Joint Surg Am 1997, 79:69-83.

11. Marco RA, Meyer BC, Kushwaha VP: Thoracolumbar burst fractures treated with posterior decompression and pedicle screw instrumentation supplemented with balloon-assisted vertebroplasty and calcium phosphate reconstruction. Surgical technique. J Bone Joint Surg Am 2010, 92(Suppl 1 Pt 1):67-76.

12. Cho DY, Lee WY, Sheu PC: Treatment of thoracolumbar burst fractures with polymethyl methacrylate vertebroplasty and short-segment pedicle screw fixation. Neurosurgery 2003, 53:1354-1360. discussion 60-1.

13. Verlaan JJ, Dhert WJ, Verbout AJ, Oner FC: Balloon vertebroplasty in combination with pedicle screw instrumentation: a novel technique to treat thoracic and lumbar burst fractures. Spine (Phila Pa 1976) 2005, 30: E73-E79.

14. Verlaan JJ, van de Kraats EB, Oner FC, van Walsum T, Niessen WJ, Dhert WJ: Bone displacement and the role of longitudinal ligaments during 
balloon vertebroplasty in traumatic thoracolumbar fractures. Spine (Phila Pa 1976) 2005, 30:1832-1839.

15. Frankel HL, Hancock DO, Hyslop G, et al: The value of postural reduction in the initial management of closed injuries of the spine with paraplegia and tetraplegia. I. Paraplegia 1969, 7:179-192.

16. Fairbank JC, Pynsent PB: The oswestry disability index. Spine (Phila Pa 1976) 2000, 25:2940-2952. discussion 52.

17. Vaccaro AR, Baron EM, Sanfilippo J, et al: Reliability of a novel classification system for thoracolumbar injuries: the thoracolumbar injury severity score. Spine (Phila Pa 1976) 2006, 31:S62-S69. discussion S104.

18. Walsh TL, Hanscom B, Lurie JD, Weinstein JN: Is a condition-specific instrument for patients with low back pain/leg symptoms really necessary? the responsiveness of the oswestry disability index, MODEMS, and the SF-36. Spine (Phila Pa 1976) 2003, 28:607-615.

19. Oner FC, Verlaan JJ, Verbout AJ, Dhert WJ: Cement augmentation techniques in traumatic thoracolumbar spine fractures. Spine (Phila Pa 1976) 2006, 31:S89-S95. discussion S104.

20. Kuklo TR, Polly DW, Owens BD, Zeidman SM, Chang AS, Klemme WR: Measurement of thoracic and lumbar fracture kyphosis: evaluation of intraobserver, interobserver, and technique variability. Spine (Phila Pa 1976) 2001, 26:61-65. discussion 6.

21. Mermelstein LE, McLain RF, Yerby SA: Reinforcement of thoracolumbar burst fractures with calcium phosphate cement. A biomechanical study. Spine (Phila Pa 1976) 1998, 23:664-670. discussion 70-1.

22. Lotz JC, Hu SS, Chiu DF, Yu M, Colliou O, Poser RD: Carbonated apatite cement augmentation of pedicle screw fixation in the lumbar spine. Spine (Phila Pa 1976) 1997, 22:2716-2723.

23. Masaki T, Sasao Y, Miura T, et al: An experimental study on initial fixation strength in transpedicular screwing augmented with calcium phosphate cement. Spine (Phila Pa 1976) 2009, 34:E724-E728.

24. Renner SM, Lim TH, Kim WJ, Katolik L, An HS, Andersson GB: Augmentation of pedicle screw fixation strength using an injectable calcium phosphate cement as a function of injection timing and method. Spine (Phila Pa 1976) 2004, 29:E212-E216.

25. Danisa OA, Shaffrey $\mathrm{Cl}$, Jane JA, et al: Surgical approaches for the correction of unstable thoracolumbar burst fractures: a retrospective analysis of treatment outcomes. J Neurosurg 1995, 83:977-983.

26. Dimar JR 2nd, Wilde PH, Glassman SD, Puno RM, Johnson JR: Thoracolumbar burst fractures treated with combined anterior and posterior surgery. Am J Orthop (Belle Mead NJ) 1996, 25:159-165.

27. Katscher S, Verheyden P, Gonschorek O, Glasmacher S: Josten C

[Thoracolumbar spine fractures after conservative and surgical treatment. Dependence of correction loss on fracture level]. Unfallchirurg 2003, 106:20-27.

doi:10.1186/1754-9493-7-3

Cite this article as: Freude et al: Safe surgical technique: cementaugmented pedicle screw instrumentation and balloon-guided kyphoplasty for a lumbar burst fracture in a 97-year-old patient. Patient Safety in Surgery 2013 7:3.

\section{Submit your next manuscript to BioMed Central and take full advantage of:}

- Convenient online submission

- Thorough peer review

- No space constraints or color figure charges

- Immediate publication on acceptance

- Inclusion in PubMed, CAS, Scopus and Google Scholar

- Research which is freely available for redistribution 